\title{
O PAPEL DO PSICOPEDAGOGO NO PROCESSO DE ENSINO- APRENDIZAGEM DO ALUNO SURDO
}

\section{ARTIGO ORIGINAL}

OLIVEIRA, Thayná Vieira de ${ }^{1}$

OLIVEIRA, Thayná Vieira de. O papel do psicopedagogo no processo de ensinoaprendizagem do aluno surdo. Revista Científica Multidisciplinar Núcleo do Conhecimento. Ano 05, Ed. 04, Vol. 02, pp. 131-136. Abril de 2020. ISSN: 2448-0959, Link de acesso: https://www.nucleodoconhecimento.com.br/educacao/papel-dopsicopedagogo

\section{RESUMO}

A preocupação básica deste estudo é refletir sobre o papel do psicopedagogo no processo ensino-aprendizagem do aluno surdo na educação infantil. Este artigo tem como objetivos analisar a importância do ensino da LIBRAS - Linguagem de Sinais na educação e a o papel do psicopedagogo frente a isso. Realizou-se uma pesquisa bibliográfica considerando contribuição de autores como Carvalho (2004), Freire (1986) e Lima (2006), entre outros, procurando enfatizar a importância da educação da LIBRAS e práticas do psicopedagogo institucional. Cessa-se a relevância de ter um psicopedagogo detectar as dificuldades que os alunos enfrentam, usando o aluno como eixo norteador para solucionar os problemas.

Palavras-chave: Psicopedagogo, ensino-aprendizagem, surdo.

\section{INTRODUÇÃO}

A presente pesquisa nutre como tema o papel do psicopedagogo no processo de ensino-aprendizagem do aluno surdo, particularmente a importância do ensino da

\footnotetext{
${ }_{1}^{1}$ Pedagoga pela Universidade Estácio de Sá - Queimados RJ e Psicopedagoga pela Faculdade Única de Ipatinga - MG.
} 
LIBRAS - linguagem de sinais dentro do meio escolar e de que modo isso influencia alunos surdos e ouvintes.

Nesta perspectiva, fundamentaram-se indagações que nortearam este artigo:

- Qual a relevância e dimensão da LIBRAS no currículo escolar na educação infantil?

- Qual deve ser a contribuição do psicopedagogo no processo de ensinoaprendizagem e sua interação professor-aluno?

Quando se pensa em currículo escolar, principalmente na educação especial, lembrase das bases para alfabetização e o início da inserção do sujeito na sociedade, sua interpretação e compreensão do que é mundo. Um processo que é progressivo e contínuo.

Neste contexto há vários elementos relevantes que fazem parte deste desenvolvimento do aluno, como o professor, pedagogo e o psicopedagogo. Um grupo de profissionais da educação que irão ajudar nesta construção de conhecimento e crescimento.

Há casos que esse desenvolvimento é mais lento devido a dificuldades e os transtornos presentes que interferem na compreensão do conteúdo. No momento em que sucede essas situações, o psicopedagogo averigua o comportamento do aluno e promove intervenções capazes de auxiliar na aprendizagem.

O papel do psicopedagogo é contribuir para uma educação de excelente qualidade e, bem como, atender as especificidades de quaisquer alunos, como no caso do aluno surdo, promovendo inclusão.

A obra final foi fundamenta nas ideologias e pareceres de autores como: Bossa (2000), Carvalho (2011), Freire (1986). Lima (2006), Paula (2004), Piletti (1999), e Veras (2015). 


\section{DESENVOLVIMENTO}

Inicialmente é preciso entender que LIBRAS significa Linguagem de Sinais Brasileira, onde se utiliza gestos e sinais como forma de comunicação para pessoas com deficiência auditiva. Ela é considerada uma língua, pois possui gramática própria e seu próprio conjunto de palavras. E cada lugar do mundo possui a sua própria língua, como a linguagem oral e escrita. Assim o indivíduo é capaz de se expressar sobre qualquer assunto.

Se tratando da comunidade surda, LIBRAS - linguagem de sinais é a sua principal e primeira língua, sendo reconhecida como língua oficial, como o português, assim dispõe na Lei n 10.436 de 24 de abril de 2002. Essas conquistas foram acontecendo aos poucos, ganhando respeito e direitos através de leis e decretos no Brasil.

No que diz respeito à educação especial, a Lei n 9.394/96 estabelece,

Art. 59. Os sistemas de ensino assegurarão aos educandos com necessidades especiais: I - currículos, métodos, técnicas, recursos educativos e organização específica, para atender às suas necessidades.

Apesar de a lei dispor que asseguram aspectos primordiais para a educação especial, ainda há evasão desses serviços com falta do profissional educacional capacitado para atender esses alunos surdos, pois inúmeros casos o profissional não apresenta conhecimento em LIBRAS e quando possui é o básico, não suficiente para ensinar.

Outro fato relevante é a falta do ensino da língua de sinais sendo parte obrigatória no currículo escolar, uma vez que entende que o ser humano é um ser comunicativo e interativo. Reflete-se a partir disso a importância de aprender a LIBRAS, como da mesma maneira aprenderia uma língua estrangeira, por exemplo, o inglês ou o espanhol.

Paula afirma que: 
As pessoas com deficiência têm os mesmos direitos que os demais cidadãos. Sociedade inclusiva para todos. A implementação da nossa visão beneficiará, não apenas as pessoas com deficiência, mas também a sociedade como um todo. (PAULA, 2004, p. 265).

Em vista disso, a inserção da LIBRAS nos currículos da educação infantil beneficiária não apenas ao aluno surdo, mas toda a turma em prol de uma capacitação coletiva e humana. No Plano Nacional de Educação Brasileira já prevê obrigatoriedade desta disciplina nos cursos de Pedagogia, Fonoaudiologia e Formação de Professores. Com isso o plano almeja promover essa disciplina em mais modalidades de ensino nos próximos anos.

O aluno surdo ao ingressar na escola já encontra dificuldade linguística, criando uma inviabilidade no ambiente escolar e possivelmente nas suas relações sociais fora da escola.

Em virtude disso, Veras pontua que:

Assim, ao se propor que a psicopedagogia institucional esteja presente tanto no pensar das práticas escolares quanto na aplicação delas, está se propondo também pensar nas micro relações dentro do contexto educacional. Dessa forma, o incentivo a ambientes educacionais estimuladores vem ao encontro da ação da psicopedagogia institucional e da compreensão de que as políticas públicas devam evidenciar em suas práticas o lugar de poder das minorias. (VERAS, 2015, p.80)

Nesse aspecto, a educação da criança surda no ambiente escolar requer atenção, pois ela começa a ser inserida em um ambiente que a maioria das pessoas possui uma cultura diferente da sua, ou seja, outra língua. É necessário entender que é através da língua que ela adquirirá conceitos e valores para o seu desenvolvimento pleno.

Então o psicopedagogo na educação infantil no âmbito escolar da educação de surdos, "deve ser levada em consideração, por exemplo, a importância da língua dos 
sinais como meio de comunicação para os surdos, e ser assegurado a todos os surdos acessos ao ensino da língua de sinais de seu país". (LIMA 2006, p. 11)

Veras afirma que:

Psicopedagogia institucional com sua interface interdisciplinar contribui na proposição de saberes e práticas escolares, assim como nos processos educacionais, atuando de forma preventiva em possíveis vieses de compreensão sobre o aluno surdo, colaborando no entendimento do surdo como ser pleno e possibilitando que suas habilidades possam emergir. (VERAS, 2006, p.86)

O psicopedagogo é capaz de fazer diferença na vivência do aluno surdo e na escola, concedendo suporte e orientação aos professores, alunos e familiares. A atuação se dará por meio de observação das dificuldades encontradas pelo aluno, em seguida um diagnóstico da situação para a busca da solução do problema.

Isso ocorrerá com atividades que reforcem o aprendizado, dando alternativas para o ensino-aprendizagem junto ao professor regente, contribuindo para inclusão dos responsáveis do aluno nas atividades propostas e criando projetos que auxiliem nessa relação da comunidade escolar a respeito do ensino da língua de sinais.

Em resumo, Bossa exemplifica:

O objetivo do tratamento psicopedagógico é o desaparecimento do sintoma e a possibilidade do sujeito aprender normalmente em condições melhores enfatizando a relação que ele possa ter com a aprendizagem, ou seja, que o sujeito seja o agente da sua própria aprendizagem e que se aproprie do conhecimento. (BOSSA, 2007, p.21)

Uma vez que essas alternativas criadas pelo profissional de educação possibilita que a criança aprenda e cria oportunidade de interação com os demais, desenvolvendo suas habilidades cognitivas e psicomotoras. Bossa (2000), acrescenta que a profissão 
do psicopedagogo não é uma atividade neutra, porque ele é um transmissor de conhecimentos e afeta tanto o aluno quanto o próprio profissional.

Lembrando que o aluno é o eixo norteador e sua relação com o professor é fundamental para o processo ensino-aprendizagem, se não há comunicação entre os principais fatores, não é possível haver uma educação de qualidade, ou seja, um professor sem conhecimento em educação especial e conhecimento em linguagem de sinais, não é capaz de haver uma aprendizagem significativa, especificamente com o aluno com deficiência auditiva.

O psicopedagogo contribui para esse dialogo professor-aluno, pois o professor é o ser primordial dentro de sala de aula. "Sua influência na sala de aula é muito grande, e a criação de um clima psicológico que favoreça ou desfavoreça á aprendizagem depende principalmente dele". (PILETTI, 1999, p. 250).

Sendo agente da transmissão de conhecimento, é importante sua atenção para as especificidades de cada aluno, influenciando de forma positiva. Compreendendo que o professor não agirá sozinho, pois há um profissional capaz de contribuir para essa formação do sujeito como um todo.

\section{CONCLUSÃO}

Em vista dos argumentos mencionados, conclui-se que a Psicopedagogia na escola possui o papel de identificar as dificuldades do aluno, buscando ações que irá contribuir para o aprendizado do aluno, através de métodos, instrumentos e técnicas próprias da psicopedagogia institucional. Enfatizando a inclusão do aluno surdo e tornando o espaço da escola um local de integração a todos.

Desta forma constatou-se que os profissionais da educação precisam compreender a importância da educação continuada, visando uma educação de qualidade e para transformação social, não somente para a realidade do aluno surdo, mas como também para uma realidade educacional com equidade. 
Nesse contexto, cabe ao psicopedagogo junto ao professor zelar para um bom convívio do aluno surdo dentro da escola, cabe a ele também intervir nos conflitos e nas dificuldades que são encontradas pelo aluno, contribuindo para construção da aprendizagem, visando resultados educacionais positivos.

\section{REFERÊNCIAS}

BOSSA, Nadia A. A Psicopedagogia no Brasil: contribuições a partir da prática. RS, Artmed, 2007. BRASIL,

BRASIL/MEC. Lei o․ 9.394, de 20 de dezembro de 1996. Lei de Diretrizes e Bases da Educação Nacional. Brasília, DF: 20 de dezembro de 1996.

BRASIL, Lei n 10.436, de 24 de abril de 2002. Dispõe sobre a Língua Brasileira de Sinais - Libras e dá outras providências. Diário Oficial da República Federativa do Brasil. Brasília, DF, 2002. Disponível em: http://www.planalto.gov.br/CCIVIL_03/Leis/2002/L10436.htm Acesso em: 24 de out. 2019.

CARVALHO, R. E. Educação inclusiva com os pingos nos "is". 7 ed. Porto Alegre: Mediação, 2011.

FREIRE, Paulo. Pedagogia do oprimido. $17^{\circ}$ ed. Rio de Janeiro: Paz e Terra, 1986.

LIMA, M.C.A et. al - Educação infantil: saberes e práticas da inclusão : dificuldades de comunicação e sinalização: surdez. 4. ed. Secretaria de Estado da Educação do Distrito Federal. [et. al.]. - Brasília: MEC, Secretaria de Educação Especial, 2006. p.11, 54. http://portal.mec.gov.br/seesp/arquivos/pdf/surdez.pdf. Acesso em: 06 de novembro de 2019.

PAULA, J. de. Inclusão: Mais do que um desafio escolar, um desafio social. São Paulo: Jairo de Paula Editora, 2004. 
PILETTI, Nelson. - Psicologia Educacional. Série Educação. São Paulo - São Paulo. Ática. 1999

VERAS, N.C.O. Psicopedagogia Institucional e Educação de Surdos no Brasil, possíveis encontros. Educação, artes e inclusão. Vol. 11, n. 1, 2015.

Enviado: Março, 2020.

Aprovado: Março, 2020. 